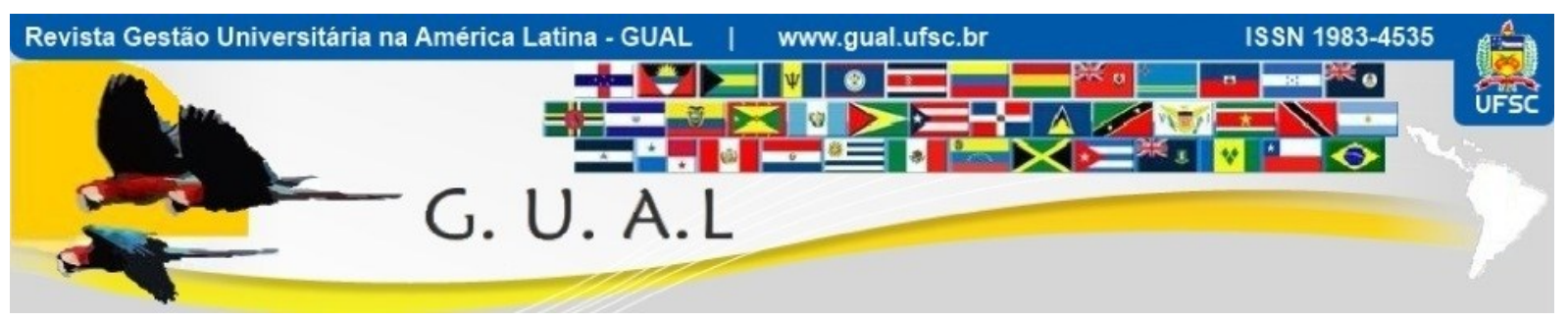

DOI: http://dx.doi.org/10.5007/1983-4535.2012v5n2p98

\title{
UNIVERSIDADE NO SÉCULO XXI: PESQUISA E ENSINO
}

\section{UNIVERSITY IN THE 21ST CENTURY: RESEARCH AND TEACHING}

Martha Abrahão Saad Lucchesi, Pós-Doutora

Universidade de São Paulo - USP mgrlucchesi@uol.com.br

Eliana Branco Malanga, Doutora Universidade Federal de São Paulo - UNIFESP ebmalanga@gmail.com

Recebido em 15/novembro/2011

Aprovado em 23/março/2012

Sistema de Avaliação: Double Blind Review

Esta obra está sob uma Licença Creative Commons Atribuição-Uso. 


\title{
RESUMO
}

O objetivo deste artigo é discutir a validade das políticas públicas adotadas pelo governo brasileiro para a educação superior na última década, analisar suas consequências na configuração da universidade para o século XXI, denominada "universidade emergente", e buscar potencialidades para a transformação do paradigma vigente na universidade atual. Para a análise, foi realizada uma pesquisa documental dos dados disponibilizados pelo Ministério da Educação do Brasil, que focalizam as políticas públicas para o setor e uma pesquisa bibliográfica utilizando textos constitucionais e legais. Recorre-se ainda, a teóricos como Duhram e Sampaio (2000), Cunha (2004), Baty (2011) e outros. O pressuposto que norteia este estudo é demonstrar a possibilidade da pesquisa na universidade (aqui conceituada como as várias categorias acadêmicas do ensino superior), diante das mudanças sociais desse início de milênio, e as transformações exigidas para a universidade, sua episteme, sua missão e seu ethos no mundo contemporâneo.

Palavras-chave: Políticas públicas. Educação superior. Universidade. Pesquisa e ensino.

\begin{abstract}
The aim of this article is to discuss the validity of public policies adopted by the Brazilian government in relation to higher education during the last decade. In addition, it will analyse its consequences in the set-up of the 21 st century university, called "emerging university", and seek possibilities to transform the paradigm of the university today. The analysis was conducted with a documentary survey of the data made available by Brazil's Ministry of Education, which focus on the public policies for the sector, and a bibliographic survey with constitutional and legal texts. We also resorted to theoreticians like Durham and Sampaio (2000), Cunha (2004), Baty (2011) and others. The study intends to demonstrate the possibility of carrying out research in the university (here understood as the various categories of higher education), in face of the social changes at the beginning of this millenium, as well as the transformations required for the university, its episteme, its mission and its ethos in the contemporary world.
\end{abstract}

Keywords: Public policies. Higher education. University. Research and teaching. 


\section{INTRODUÇÃO}

Políticas públicas são as executadas pelo Estado em favor do interesse público, dos direitos humanos ou do desenvolvimento econômico, social ou cultural da sociedade. Segundo Bucci (2006, p. 13), “Os elementos das políticas públicas são o fím da ação governamental, as metas nas quais se desdobra esse fim, os meios alocados para a realização das metas e, finalmente, os processos de sua realização".

Bobbio (1997, p. 25) entende que o Estado é o monopolizador da força organizada e também o guardião da soberania. O autor refere-se à "política de Estado", conceituando "política" como forma de atividade humana intimamente ligada ao poder. Cabe ao Estado intervir na sociedade de modo a garantir os direitos estabelecidos na Constituição, pois "o problema do nosso tempo é proteger os direitos do cidadão, tanto no campo jurídico como no político.”. A concretização dos direitos do cidadão ocorre por meio das políticas públicas.

O objetivo deste artigo é discutir a validade das políticas públicas para a educação superior adotadas pelo governo brasileiro na última década, analisar suas consequências na configuração da nova universidade, chamada "universidade emergente", e buscar potencialidades para a transformação do paradigma vigente na universidade brasileira.

Compreende-se que o ethos da universidade no início do século XXI se configura como centro produtor e difusor do conhecimento.

Assim como acreditamos na universidade como um campo de pesquisa, pulsante, em que a vida se expressa nas indagações dos estudantes, também consideramos que a educação não se limita a transmitir conhecimentos, mas sim preparar os espíritos para toda a vida. Afirma-se que, "o paradigma da universidade emergente, que estabelece que a pesquisa está imbricada no ensino, é o melhor caminho para adequar o ensino superior às exigências do mundo do atual.". (LUCCHESI; MALANGA, 2010a, p. 120).

Consoante Lucchesi (2002), a "universidade emergente" não é apenas um lugar de ensino e transmissão de conhecimento acumulado, mas também o centro produtor de conhecimento pela pesquisa institucional, da qual dependem o ensino e a extensão. O novo paradigma, a ruptura epistemológica, têm como pressuposto que a pesquisa é o próprio ensino (LUCCHESI, 2006, p. 53).

A análise sobre o conceito de paradigma remonta às ideias de Platão, e nesse sentido não se configura apenas como um modelo, um padrão a ser copiado ou uma amostra de algo real; é muito mais que isso: é um modelo exemplar, perfeito, a ser seguido. 
Um paradigma delineia, define um quadro epistêmico, um arcabouço conceitual, um conjunto de referências capaz de conduzir as investigações científicas durante certo período de tempo. Seria um tipo de construção que põe fim às controvérsias existentes na área a respeito de determinados fundamentos ou o "próprio princípio de organização das teorias" (MORIN, 2001, p. 145).

Sobre paradigmas de produção do conhecimento e rupturas epistemológicas, pode-se citar Foucault (2010, p. 13), que constata a possibilidade de "discernir as rupturas e o nascimento de novos saberes.”. Conforme o autor, cada época se caracteriza por uma “configuração geral dos saberes", e esta "determina o que pode ser pensado, como pode ser pensado, dentro de quais critérios e em qual ordem".

Atualmente busca-se a superação do paradigma vigente na produção do conhecimento e nas relações sociais, pois existe uma relação profunda entre a forma pela qual organizamos o conhecimento e sua produção e a forma como organizamos a sociedade. O paradigma produz e reproduz uma determinada cultura da separação, da disjunção e da oposição. Nesse contexto histórico de mudanças e rupturas, a universidade, como foi normatizada pelas leis no Brasil, valida-se pela excelência de sua produção do conhecimento científico. A relação entre o ensino e a pesquisa na universidade é epistemológica, e isso não se trata de um conceito ou de uma opção, mas de um dado essencial que, se for ignorado, não legitima o ensino em nível superior. Entretanto, além de existirem, essas funções precisam estar integradas, de tal maneira que não se possa pensá-las separadamente.

Muitas Instituições de Ensino Superior (IES), no entanto, não percebem que a Constituição fixa um conceito importante de ensino superior ao valorizar a pesquisa e a extensão, sendo que a primeira não se restringe ao âmbito da universidade, podendo também se desenvolver nas empresas e nos centros de pesquisa. Valorizar a produção de conhecimento pela ciência e tecnologia vem da compreensão de que, atualmente, esses são os pontos determinantes para a inserção da nação na comunidade internacional.

Este trabalho analisa os dados disponibilizados pelo Ministério da Educação do Brasil à luz de teorias já aceitas pela comunidade acadêmica, configurando o uso do método dedutivo. Como técnicas, foram empregadas a pesquisa documental dos dados que focalizam as políticas públicas para o setor e a pesquisa bibliográfica de textos constitucionais, legais e de autores do campo jurídico. Na análise do ensino superior recorre-se a Duhram e Sampaio (2000), Baty (2011) e outros. O conceito de paradigma é fundamentado em Morin (2001) e em Foucault (2010). 


\section{A EDUCAÇÃO SUPERIOR NA CONSTITUIÇÃO DE 1988}

A Constituição da República Federativa do Brasil de 1988 não obriga o Estado a oferecer o ensino superior gratuito, mas considera seu dever garantir, de acordo com o art. 208 (caput e inciso V), “[...] acesso aos níveis mais elevados do ensino, da pesquisa e da criação artística, segundo a capacidade de cada um" (BRASIL, 1988).

Ressalte-se que, embora a educação superior não seja uma atribuição exclusiva do Estado, cabe-lhe estabelecer as políticas públicas que garantam os direitos assegurados na Constituição. Inexistindo a obrigatoriedade de oferta gratuita de ensino superior, podem os governos optar por aumentar o oferecimento de vagas nas instituições públicas ou incentivar a ampliação no âmbito do ensino privado.

Conforme Ranieri (2000, p. 24-25), a Lei de Diretrizes e Bases da Educação Nacional (LDB) “é o eixo jurídico da organização do ensino no país”. De acordo com Reale (1981, p. 143), “a Lei de Diretrizes e Bases é a verdadeira lei complementar, dado o seu caráter integrador da vontade constitucional.”. A seguir, a figura 1 demonstra a subdivisão estabelecida nas categorias administrativas pela LDB/1996.

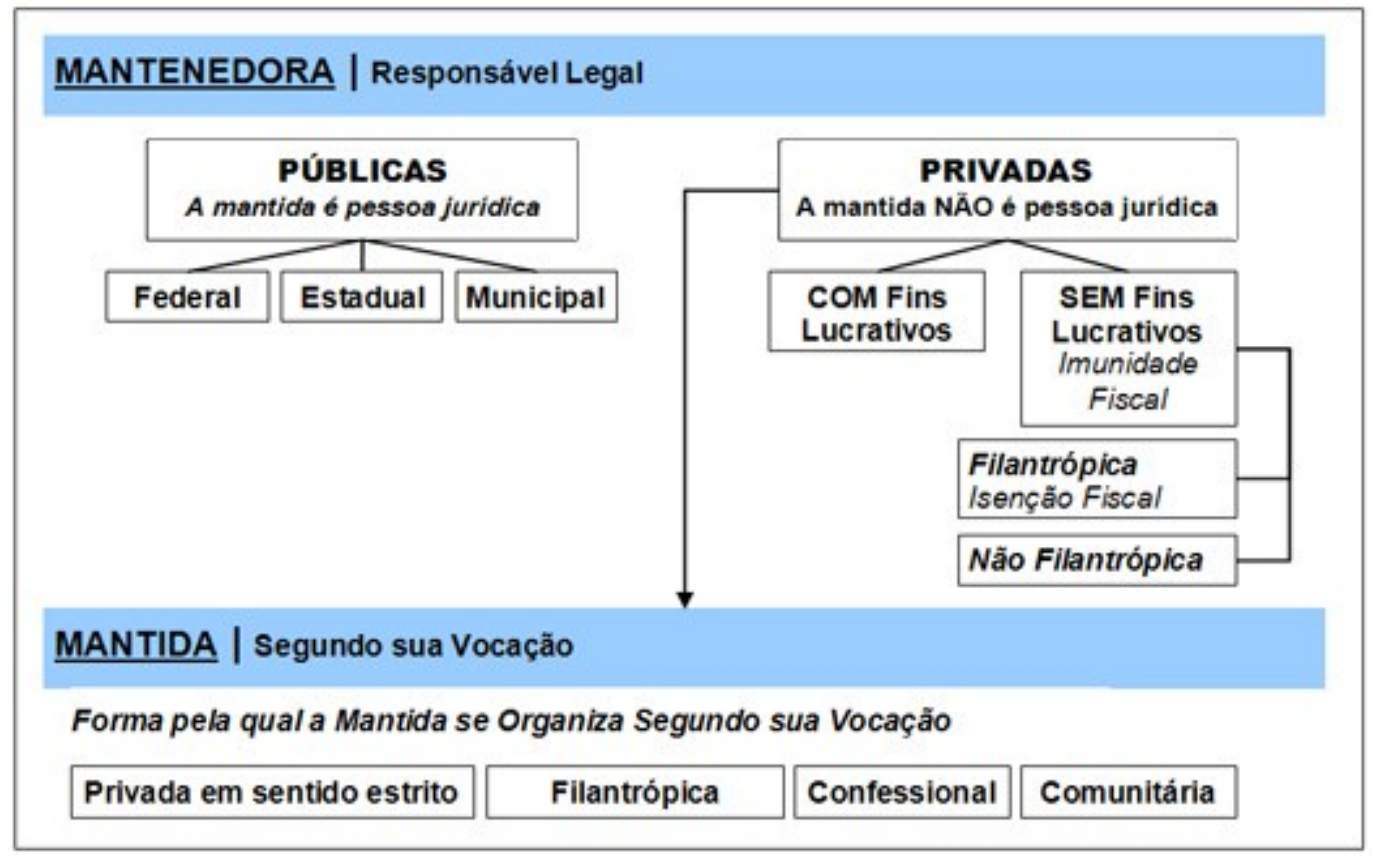

Figura 1 Estrutura do ensino superior brasileiro Fonte: Brasil (2009b).

Para a Lei de Diretrizes e Bases da Educação, são consideradas instituições privadas de ensino superior as "mantidas e administradas por pessoas físicas ou jurídicas de direito privado". Podem se organizar como: particulares em sentido estrito (com fins lucrativos), 
comunitárias (sem fins lucrativos), confessionais (de caráter religioso) e filantrópicas (caracterizadas como instituições que visam ao bem social, agindo de forma complementar às atividades de Estado).

As instituições de ensino superior de caráter público são as criadas, mantidas e administradas pelo poder público, ou por ele incorporadas. Podem ser federais, quando mantidas e administradas pelo governo federal, estaduais, quando mantidas e administradas pelos governos estaduais, ou municipais, quando mantidas e administradas pelo poder público municipal (BRASIL, 2011a).

Para Duhram e Sampaio (2000, p. 3-5), o Brasil possui uma configuração sui generis na sua dinâmica da relação de interdependência entre ensino público e privado, havendo entre eles não uma oposição, mas antes uma complementaridade em decorrência dos processos de expansão do sistema de ensino superior e das políticas públicas adotadas nas últimas décadas.

Durham e Sampaio (2000, p. 5) classificam ainda as instituições privadas em "mais seletivas" e "menos seletivas", afirmando que a últimas visam atender à demanda dos estudantes, os quais não conseguem ingressar nas primeiras e buscam carreiras de alta demanda.

Os dados do Censo do Ensino Superior de 2008 permitem observar, em relação à organização acadêmica, um incremento de 3,2\% no número de centros universitários em relação a 2007 e um ligeiro decréscimo no número de faculdades. No entanto, as instituições (faculdades, escolas, institutos, faculdades integradas, centros federais de educação tecnológica e faculdades de tecnologia), conforme os anos anteriores, mantiveram o predomínio, com quase 2.000 estabelecimentos, correspondentes a $86,4 \%$ do total de IES, enquanto as universidades e centros universitários respondem por $8,1 \%$ e $5,5 \%$, respectivamente (BRASIL, 2008).

Como se pode observar, o ensino superior brasileiro é predominantemente constituído por escolas isoladas e afins; apesar disso, grande parte da demanda é absorvida pelas grandes universidades.

Ressalte-se que as universidades adquiriram maior autonomia nos termos da LDB/1996, art. 53, o que implica maior capacidade para adaptarem-se às permanentes mudanças do cenário social e econômico, nacional e internacional. Entretanto, nem todas elas souberam aproveitar essa autonomia (BRASIL, 1996).

A LDB/1996, art. 53, estabelece ainda a autonomia universitária, permitindo-lhes, de acordo com o inciso I, "criar, organizar e extinguir, em sua sede, cursos e programas de 
educação superior". Essa liberdade, contudo, está restrita pela "obediência às normas gerais da União" (BRASIL, 1996). Também para os programas dos cursos existe certa autonomia, desde que respeitados os currículos mínimos estabelecidos pelos órgãos federais competentes.

A autonomia universitária para a criação de vagas permite maior agilidade sem depender de aprovação prévia dos órgãos federais. Isso, segundo as diretrizes oficiais, levaria ao atendimento das necessidades regionais e locais de ensino universitário, e à sua expansão por todo o país. Visando a uma melhor qualidade do ensino, tal autonomia foi concedida apenas às universidades e aos centros universitários. As primeiras se definem pela tríade ensino - pesquisa - extensão. Assim, faz parte da autonomia universitária "estabelecer planos, programas e projetos de pesquisa científica, produção artística e atividades de extensão" de acordo com o inciso III do mesmo art. 53 da LDB (BRASIL, 1996).

\section{AS POLÍTICAS PÚBLICAS DO ATUAL GOVERNO}

As políticas públicas adotadas em anos recentes, a partir de 2003, apresentam alguma continuidade em relação a políticas anteriores, mudando sua forma ou seu coeficiente de avaliação. O controle do MEC vem aumentando progressivamente, e compete às IES cumprilas nos termos da legislação vigente. Como exemplo, podemos citar o princípio de avaliação permanente das instituições de ensino superior.

Em 1996, foi instituído o Exame Nacional de Cursos, conhecido como "Provão", que, conforme Cunha,

Foi o único tipo de avaliação efetivamente implantado, com alcance geral, e, mesmo assim, de modo progressivo - em média, a cada ano três novos cursos, desde 1996. Embora consistisse em provas aplicadas aos concluintes da graduação, seu objetivo era o de avaliar os cursos e, em decorrência, as próprias instituições. (2004, p. 5).

A partir de 2003, a metodologia de avaliação foi totalmente modificada. O Sistema Nacional de Avaliação da Educação Superior (Sinaes) foi criado pela Lei n. ${ }^{\circ} 10.861$, de 14 de abril de 2004, e é composto por três aspectos principais: a avaliação das instituições, dos cursos e do desempenho dos estudantes, sob os seguintes aspectos: ensino, pesquisa, extensão, responsabilidade social, desempenho dos alunos, gestão da instituição, corpo docente, instalações e vários outros aspectos (BRASIL, 2011a).

As informações obtidas pelo Sinaes são sistematizadas e seriadas de modo a permitir uma perspectiva temporal. Esses dados são utilizados pelos órgãos governamentais para orientar políticas públicas, mas também estão disponíveis para alunos, instituições acadêmicas 
e público em geral (BRASIL, 2004). É discutível a eficácia do atual sistema de avaliação por amostragem na elaboração de políticas públicas para o setor. Deve-se considerar que, para a sociedade, desde o início, com o Provão, o ranking das IES permitiu a opção dos estudantes pelas instituições mais conceituadas nas avaliações anuais.

A política pública mais discutida pelos acadêmicos e pela sociedade atualmente é uma proposta de reformulação do Exame Nacional do Ensino Médio (ENEM), o qual foi apresentado pelo Ministério da Educação em 2010, e sua utilização como forma de seleção unificada nos processos seletivos das universidades públicas federais e de todas as IES que aderiram a esse sistema. Segundo o Ministério da Educação, “A proposta tem como principais objetivos democratizar as oportunidades de acesso às vagas federais de ensino superior, possibilitar a mobilidade acadêmica e induzir a reestruturação dos currículos do ensino médio." (BRASIL, 2011b). O ENEM foi criado para ser um sistema de avaliação do ensino médio, e permanece ainda inconclusiva sua eficácia como política pública de democratização e acesso, tanto quanto sua viabilidade como substituto do vestibular, que é ainda adotado pelas IES mais tradicionais, sendo o ENEM considerado sistema mais justo para os estudantes que concorrem a uma vaga na IES selecionada. Pesquisas e análises mais conclusivas serão necessárias para se afirmar a validade do argumento de democratização.

Uma das principais metas das políticas públicas para o ensino superior no Brasil de hoje é o aumento do número de alunos no país. Pelos dados oficiais, estes totalizavam 5.954.021 em 2009. Até 2020, pretende-se atingir a marca de dez milhões de alunos. A meta é ambiciosa se considerarmos que no Censo de Educação 2009 temos apenas 1.797.434 concluintes do ensino médio para uma oferta de vagas de 3.164.679 para o ensino superior, com 6.223.430 candidatos inscritos e com 1.511.388 ingressantes, portanto inferior ao de concluintes do ensino médio (BRASIL, 2009a). Dessa ótica, para que sejam atingidas as metas governamentais, faltam 4.045.979 alunos (ANDIFES, 2011, p. 13).

Dois dados demonstram o porquê da impossibilidade de se atingir esse objetivo de dez milhões de alunos: o primeiro é o fato de sobrarem vagas no ensino superior. O Censo da Educação Superior (MEC/INEP, 2009) informa que, de cada cem vagas autorizadas no ensino superior brasileiro, 49 ficam ociosas, pois o número de vagas é superior ao número de concluintes do ensino médio e nem todos se encaminham para o superior. O segundo dado é o fato de não haver estudantes com disponibilidade financeira para ocupar as vagas disponíveis, pois elas estão no sistema privado de ensino, não no sistema público gratuito (salvo algumas exceções). 
Há, ainda, um terceiro aspecto ao apontar o decréscimo do número de pessoas que, anualmente, ingressam no ensino superior. Desde o início do atual governo os números vêm caindo e a situação ainda não é irreversível devido aos programas de apoio criados tanto no âmbito do governo federal quanto no dos estados. Isso se justifica, pois o ensino superior é um investimento; mesmo a universidade pública e gratuita implica sacrifícios para o estudante, que exige retorno em conhecimento. O mercado de trabalho, por sua vez, retraído e seletivo, faz cada vez mais exigências, requer qualidade, e os alunos selecionam a instituição de ensino em função do seu prestígio, o qual se obtém com pesquisa constante e relevante. Assim, cria-se um círculo virtuoso, o qual obrigará as instituições de ensino superior que desejarem permanecer e contribuir com a sociedade a investirem em produção de conhecimento.

\section{A IMPORTÂNCIA DA PESQUISA NA AVALIAÇÃO INSTITUCIONAL}

A relação entre o desenvolvimento de pesquisa institucional e a qualidade de ensino vem sendo exaustivamente comprovada, não apenas por estudos específicos sobre o tema como também pelos sucessivos resultados do Provão - que iniciou o ciclo de avaliação - e, atualmente, pelo Enade, que, apesar de todas as críticas das quais tem sido alvo, constituiu-se em ação governamental de políticas de avaliação, e mais recentemente como parâmetro da sociedade na opção por uma instituição de ensino superior.

A busca do status de universidade não visa apenas ao aspecto formal de atendimento às diretrizes governamentais, mas também leva em conta as exigências da sociedade. Hoje é o candidato quem seleciona a instituição de ensino superior. A situação inverteu-se, pois há mais vagas do que candidatos nas instituições privadas, denominadas "nominais" quando não demonstram qualidade de ensino. A política de ampliação de oferta de vagas que devem ser custeadas pelo educando, num momento de recessão e desemprego, resultou num excesso de oferta. Como consequência, o ingressante pode escolher qual IES quer cursar e tende a fazê-lo em função do prestígio da instituição de ensino.

Evidencia-se que o discurso de poder gerado pela educação superior está transitando de um paradigma de repetição do conhecimento, herdado da universidade medieval, e caminhando para o paradigma de produção do conhecimento como base do ensino. Algumas instituições de ensino superior já adotaram o novo paradigma, e outras estão em busca de um caminho. De acordo com Altbach (2007, p. 3 apud LUCCHESI; MALANGA, 2010b, p. 35), a "universidade de pesquisa é a instituição central do século 21 , essencial para a criação e 
difusão do conhecimento". Embora o autor ainda use a expressão "universidade de pesquisa", o que leva a supor a existência de universidades sem pesquisa, ele esclarece que esta não é a realidade do século XXI.

Neste início de século, em que se entende a necessidade internacional de se produzir conhecimento e no qual o ethos da universidade se configura como centro produtor e difusor do conhecimento, pode-se afirmar que "a pesquisa é o próprio ensino" (LUCCHESI; MALANGA, 2010a, p. 116); esta deve ser permanentemente a base de sustentação do ensino, enriquecendo-se e realimentando-se dele (LUCCHESI; MALANGA, 2010a, p. 122).

As universidades públicas brasileiras que obtêm prestígio internacional são as que se destacam em produção de conhecimento. Esse é o parâmetro da avaliação. Percebe-se que o paradigma da universidade já predomina em nível internacional como produtora e difusora do conhecimento. Nas palavras de Baty (apud MARINHEIRO, 2001), "Para estar na elite do ensino mundial é preciso produzir conhecimento que seja relevante para o mundo, não basta formar profissionais".

Em sentido contrário, temos as instituições de ensino que buscam o lucro imediato e não são capazes de perceber a função do ensino superior: produzir e difundir o conhecimento. Estas tendem à extinção. O processo já começou, e as fusões e aquisições acompanham a tendência das grandes corporações em nível global.

É preciso ressaltar que existe ainda um potencial de crescimento do número de estudantes em curso superior no Brasil. Entretanto, para que um aluno faça um investimento na educação em nível superior, é preciso haver uma expectativa de retorno profissional, o qual só ocorre quando a IES é prestigiada e de excelência. Os candidatos à educação superior estão percebendo esse fenômeno e, quando não conseguem ingressar em uma instituição de melhor qualidade, preferem ficar sem estudar, podendo causar às IES que não primam pela qualidade o encerramento de suas atividades.

Algumas universidades privadas ampliaram significativamente sua produção de conhecimento. Para serem capazes de implantar pesquisa em curto espaço de tempo, para cumprir demandas dos órgãos oficiais, e sem dispor de conhecimento necessário, muitas instituições privadas têm contratado professores/pesquisadores das IES públicas no sentido de constituir grupos de pesquisa. O trabalho é árduo e dispendioso, pois muitas vezes a "cultura institucional", voltada apenas para o ensino sem pesquisa, torna-se resistente à inovação. Nesse sentido, Lucchesi (2011, p. 29) afirma que 
o conhecimento criado pelas instituições de ensino superior deve incluir a reflexão sobre a sociedade, como resposta às demandas dessa mesma sociedade e também, a rigorosa autocrítica, para que a comunidade universitária saiba definir suas finalidades e assumir seus compromissos.

As políticas públicas no Brasil precisam ampliar as condições para a produção do conhecimento, do qual dependem tanto a qualidade do ensino superior como o processo de desenvolvimento do país.

\section{CONSIDERAÇÕES FINAIS}

A política de avaliação comprovou o que já era conhecido pelos acadêmicos: o ensino de excelência tem como base a pesquisa. Ao pesquisar, o professor pode rever os fundamentos da matéria, levando ao aluno novos conhecimentos e ensinando-o a buscar o seu próprio conhecimento.

A análise demonstra que as IES privadas, quando fazem pesquisa, alcançam maior prestígio e, como consequência, obtêm maior demanda, selecionando os melhores candidatos, o que leva a melhores resultados no Enade e aumentando ainda mais o prestígio e a procura por essas instituições, criando assim um círculo virtuoso.

A transformação é urgente, crucial e factível, pois já existem em nosso país alguns centros produtores de conhecimento. É preciso preservá-los, apóia-los e ampliá-los para que essa produção aumente ainda mais.

É esse o momento de escolha: as IES que tiverem qualidade - a qual só se obtém com produção do conhecimento, ou seja, investimento em pesquisa - terão alunos; as outras tenderão à extinção. Quanto tempo demorará esse processo dependerá das novas políticas públicas que podem vir a ser implantadas, mas o fenômeno apresenta-se, atualmente, irreversível.

Evidencia-se que a essência da universidade, do ensino superior, é a produção do conhecimento.

O ethos da universidade para o século XXI tem como pressuposto que a pesquisa é o próprio ensino.

\section{REFERÊNCIAS}

ANDIFES, Associação Nacional dos Dirigentes das Instituições Federais de Ensino Superior. Expansão estratégica da educação superior brasileira: ação conjunta das entidades representativas dos setores público e particular: o desafio de colocar 10 milhões de estudantes no ensino superior. SEMINÁRIO ABMES. Brasília, 31 de maio de 2011. Disponível em: 
$<$ http://www.abmes.org.br/abmes/public/arquivos/documentos/Seminario-2011-05-31Andifes.pdf>. Acesso: 29 out. 2011.

BOBBIO, Norberto. Estado, governo e sociedade: para uma teoria geral da política. Rio de Janeiro: Paz e Terra, 1997.

BRASIL. Constituição (1988). Constituição da República Federativa do Brasil: promulgada em 5 out. 1988. Brasília. Presidência da República. Disponível em:

$<$ http://www.planalto.gov.br/ccivil_03/constituicao/principal.htm>. Acesso em: 20 out. 2011.

. Lei $n^{\circ} 10.861$, de 14 de abril de 2004. Institui o Sistema Nacional de Educação

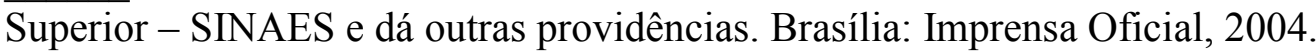

. Lei $n^{\circ}$ 9.394, de 20 de dezembro de 1996. Estabelece as Diretrizes e Bases da Educação Nacional. Brasília: Ministério da Educação, 1996. Disponível em:

$<$ http://www.planalto.gov.br/ccivil_03/LEIS/19394.htm>. Acesso em: 10 set. 2011.

. Instituto Nacional de Estudos e Pesquisas Educacionais Anísio Teixeira (Inep).

Censo da educação superior 2008. Brasília: MEC/Inep, 2008. Disponível em:

$<$ http://download.inep.gov.br/download/censo/2008/resumo_tecnico_2008_15_12_09.pdf >. Acesso em: 20 ago. 2009.

. Instituto Nacional de Estudos e Pesquisas Educacionais Anísio Teixeira (Inep).

Censo da educação superior 2009. Brasília: MEC/Inep, 2009a. Disponível em:

$<$ http://download.inep.gov.br/download/superior/censo/2009/resumo_tecnico2009.pdf $>$. Acesso em: 20 ago. 2009.

. Instituto Nacional de Estudos e Pesquisas Educacionais Anísio Teixeira (Inep).

Dados educação superior. 2009b. Disponível em:

$<$ http://www.educacaosuperior.inep.gov.br/tipos_de_instituicao.stm>. Acesso em: 26 mar. 2009.

Instituto Nacional de Pesquisa Educacionais Anísio Teixeira (Inep). Portaria normativa $n^{\circ}$ 40, de 12 de dezembro de 2007. 6 jan. 2011a. Disponível em:

$<\mathrm{http}$ ://download.inep.gov.br/educacao_superior/censo_superior/legislacao/2007/portaria_40 12122007.pdf>. Acesso em: 27 set. 2011.

Ministério da Educação. Enem - Novo Enem. 2011b. Disponível em:

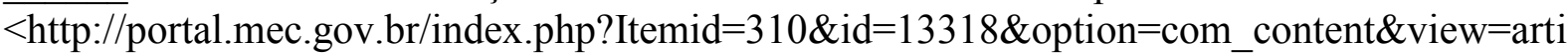
cle>. Acesso em: 28 out. 2011.

CUNHA, L. A. Desenvolvimento desigual e combinado no ensino superior: Estado e mercado. Educ. Soc., Campinas, v. 25, n. 88, p. 795-817, especial - out. 2004. p. 795-817. Disponível em: <http://www.cedes.unicamp.br>. Acesso em: 10 out. 2011.

DALLARI, Dalmo de Abreu. Elementos de teoria geral do Estado. São Paulo: Saraiva, 2003.

DURHAM, Eunice Ribeiro; SAMPAIO, Helena. O setor privado de ensino superior na América Latina. Cadernos de Pesquisa, n. 110, p. 7-37, jul./2000. 
FOUCAULT, Michel. Les mots et les choses. Paris: Gallimard, 2010. 400 p.

LUCCHESI, Martha A. S. La Universidad Internacional en América Latina: un nuevo paradigma para el siglo XXI. Formación Universitária, v. 4, p. 25-36, 2011. Disponível em: $<$ http://www.scielo.cl/pdf/formuniv/v4n1/art05.pdf >. Acesso em: 15 ago. 2011.

La universidad brasileña en un contexto de cambios impuesto por la globalización Revista de la Educación Superior, Anuies/México, v. xxxv (1, n. 137, p. 99-109, 2006. (Unesco: Bibliographie sélective, Internationalisation et enseignement supérieur, 2006). Disponível em: <http://redalyc.uaemex.mx/redalyc/pdf/604/60413708.pdf >. $<$ www.unesco.org/iau/internationalization/rtf/i_bib1.rtf $>$. Acesso em: 15 ago. 2011.

. Universidade no limiar do terceiro milênio. Santos: Leopoldianum, 2002.

LUCCHESI, Martha Abrahão Saad; MALANGA, Eliana Branco. Universidade do século XXI: prática/pesquisa e ensino. Revista Didática Sistêmica, v. 12, 2010a, p. 110-127. Disponível em: <www.seer.furg.br/ojs/index.php/redsis/article/viewFile/1826/1011>. Acesso em: 27 out. 2011.

Perceptions of higher education in Brazil in the first decade of the third millennium. US-China Education Review, v. 7, p. 31-44, 2010b. Disponível em:

$<$ http://www.airiti.com/ceps/ec_en/ecjnlarticleView.aspx?jnlcattype=0\&jnlptype=0\&jnltype $=$ $0 \&$ jnliid $=3445 \&$ issueiid $=96603 \&$ atliid $=2026345>$. Acesso em: 22 set. 2011 .

MARINHEIRO, Vaguinaldo. Pesquisa impulsiona avanço de USP em ranking; leia entrevista. Folha de São Paulo, 5 out. 2011. Disponível em:

$<$ http://www1.folha.uol.com.br/saber/986237-pesquisa-impulsiona-avanco-de-usp-emranking-leia-entrevista.shtml>.

MORIN, Edgar. Introdução ao pensamento complexo. 3. ed. Lisboa: Instituto Piaget, 2001.

RANIERI, Nina Beatriz. Educação superior, direito e Estado: na lei de Diretrizes e Bases (Lei nº 9.394/96). São Paulo: Edusp, Fapesp, 2000.

REALE, Miguel. Questões de Direito. São Paulo: Sugestões Literárias, 1981.

Conceito normativo de "universidade" no Brasil: Nos termos da LDB, 9394/96, juridicamente as universidades "são instituições pluridisciplinares de formação dos quadros profissionais de nível superior, de pesquisa, de extensão e de domínio e cultivo do saber humano". Dispõe a Lei que elas são caracterizadas pela "produção intelectual institucionalizada mediante o estudo sistemático dos temas e problemas mais relevantes, tanto do ponto de vista científico e cultural, quanto regional e nacional" (art. 52, I), pela existência de um terço do corpo docente com titulação acadêmica de mestrado ou doutorado (art. 52, II) e igual porção em regime de tempo integral (art. 52, III). Dentre suas atribuições, no exercício de sua autonomia, ressaltamos a de "estabelecer planos, programas e projetos de pesquisa científica, produção artística e atividades de extensão" (art. 53, III) e a de decidir, por meio de seus colegiados de ensino e pesquisa, sobre "contratação e dispensa de professores" (art. 53, parágrafo único, V) e sobre "planos de carreira docente" (art. 53, parágrafo único, VI). Tais normas, a rigor, decorrem do mandamento sobre a "indissociabilidade entre ensino, pesquisa e extensão" que afinal justificam outro princípio, o da "autonomia didático-científica, administrativa e de gestão financeira e patrimonial" (Constituição Federal, 1988, art. 207). Não obstante, sob a ótica constitucional, a questão das universidades também deve atender ao que estabelece o art. 174: "Como agente normativo e regulador da atividade econômica, o Estado exercerá, na forma da lei, as funções de fiscalização, incentivo e planejamento, sendo este determinante para o setor público e indicativo para o setor privado" (PARECER $\mathrm{CNE} / \mathrm{CES} \mathrm{n}{ }^{\circ} 37 / 2007$, grifo nosso). 